\title{
Notes on the vocalizations of Scarlet-bellied Mountain-tanager (Anisognathus igniventris)
}

\section{Peter Boesman}

In the following we briefly analyze and compare voice of the different races of Scarlet-bellied Mountain-tanager (Anisognathus igniventris). We also try to quantify the extent of any vocal differences using the criteria proposed by Tobias et al. (2010), as a support for taxonomic review. We have made use of sound recordings available on-line from Xeno Canto (XC) and Macaulay Library (ML).

An overview of song per race, illustrated with sonograms:

lunulatus (Andes of W Venezuela (S Táchira) and adjacent Colombia (Norte de Santander S in E Andes to Cundinamarca)

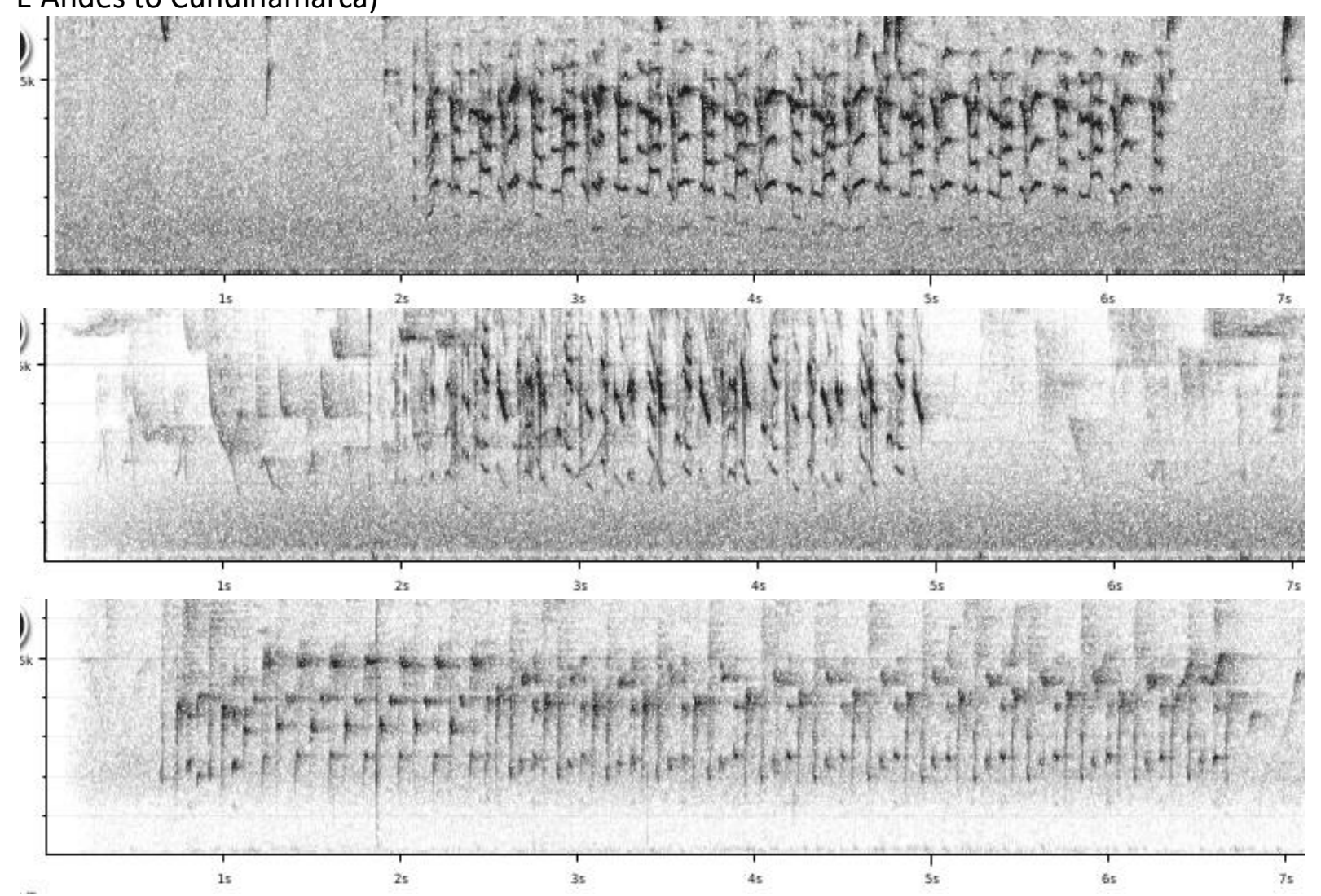




\section{HANDBOOK OF THE \\ Alve}

\section{ORNITHOLOGICAL NOTES}

erythrotus (C Andes of Colombia (Caldas, Cauca, Huila, and both slopes in Nariño) S through Ecuador to $\mathrm{N}$ Peru ( $\mathrm{N}$ of $\mathrm{R}$ Marañón, $\mathrm{S}$ to $\mathrm{R}$ Chamaya)
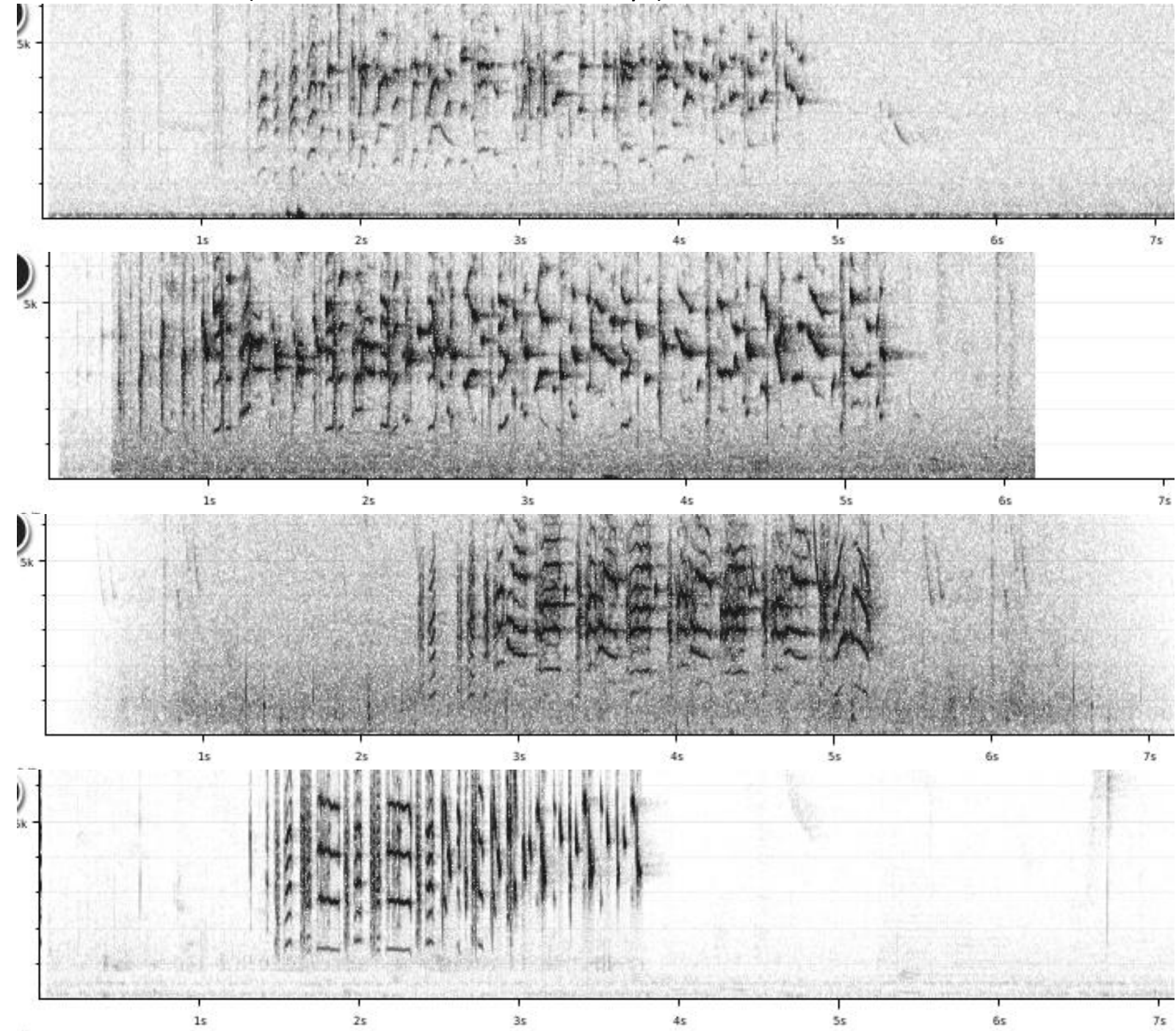

\section{5}

(1)

65

ignicrissa (E slope of Andes of Peru S of R Marañón (C Cajamarca S of R Chamaya, and from Amazonas S to Junín)

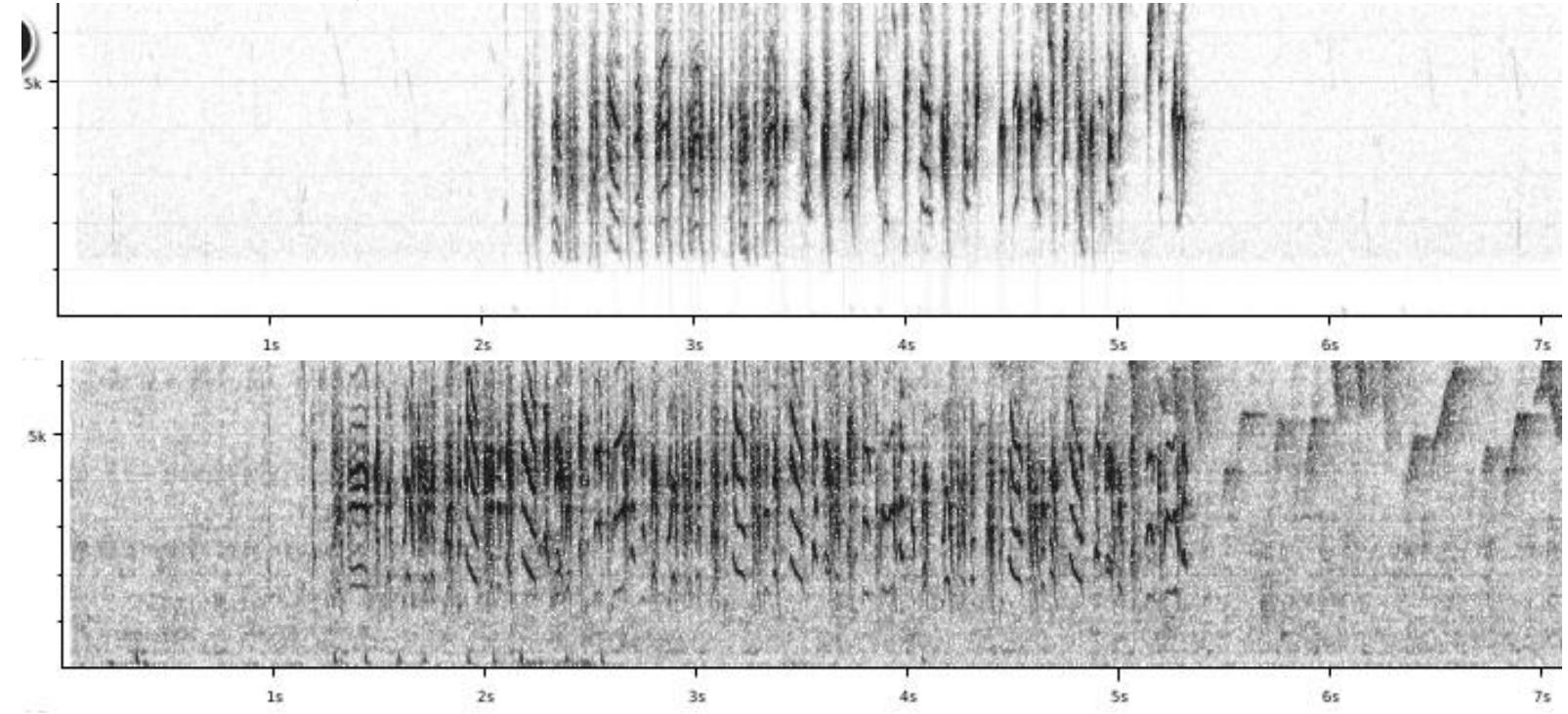




\section{HANDBOOK OF THE \\ Allive}

\section{ORNITHOLOGICAL NOTES}

igniventris (E slope of Peru (from Junín) S to Bolivia (Santa Cruz)
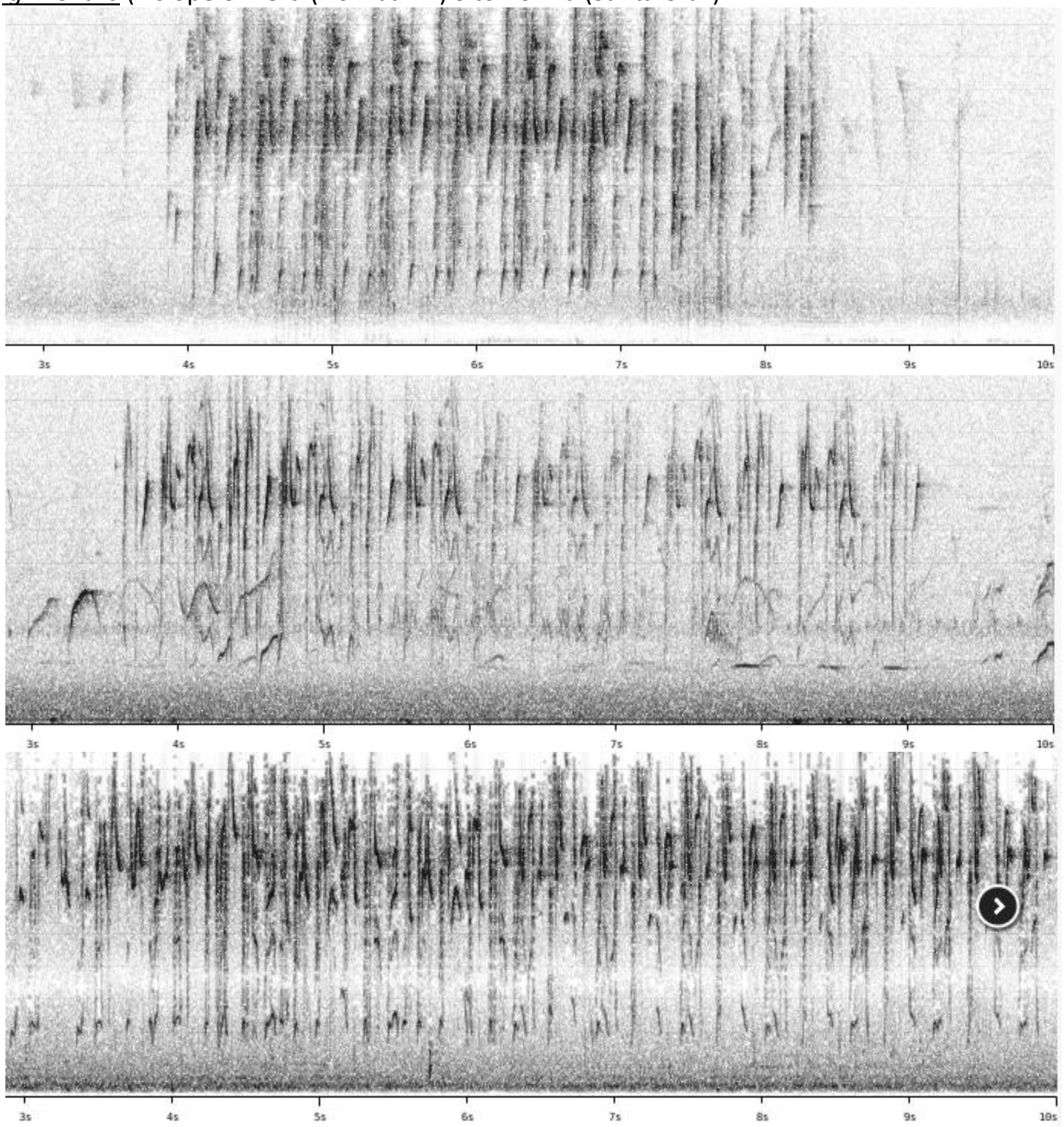

Song of igniventris is very different, being much higher pitched (most energy in range 5$10 \mathrm{kHz}$ vs below $6 \mathrm{kHz}$ in other races, score 3 based on max. frequency) and lacking nasal or twangy notes (score 1). Application of Tobias criteria would lead to a total score of about 4.

The change in song occurs in Junín, Peru, with apparently a narrow 'hybrid zone' NE of Huancayo: 

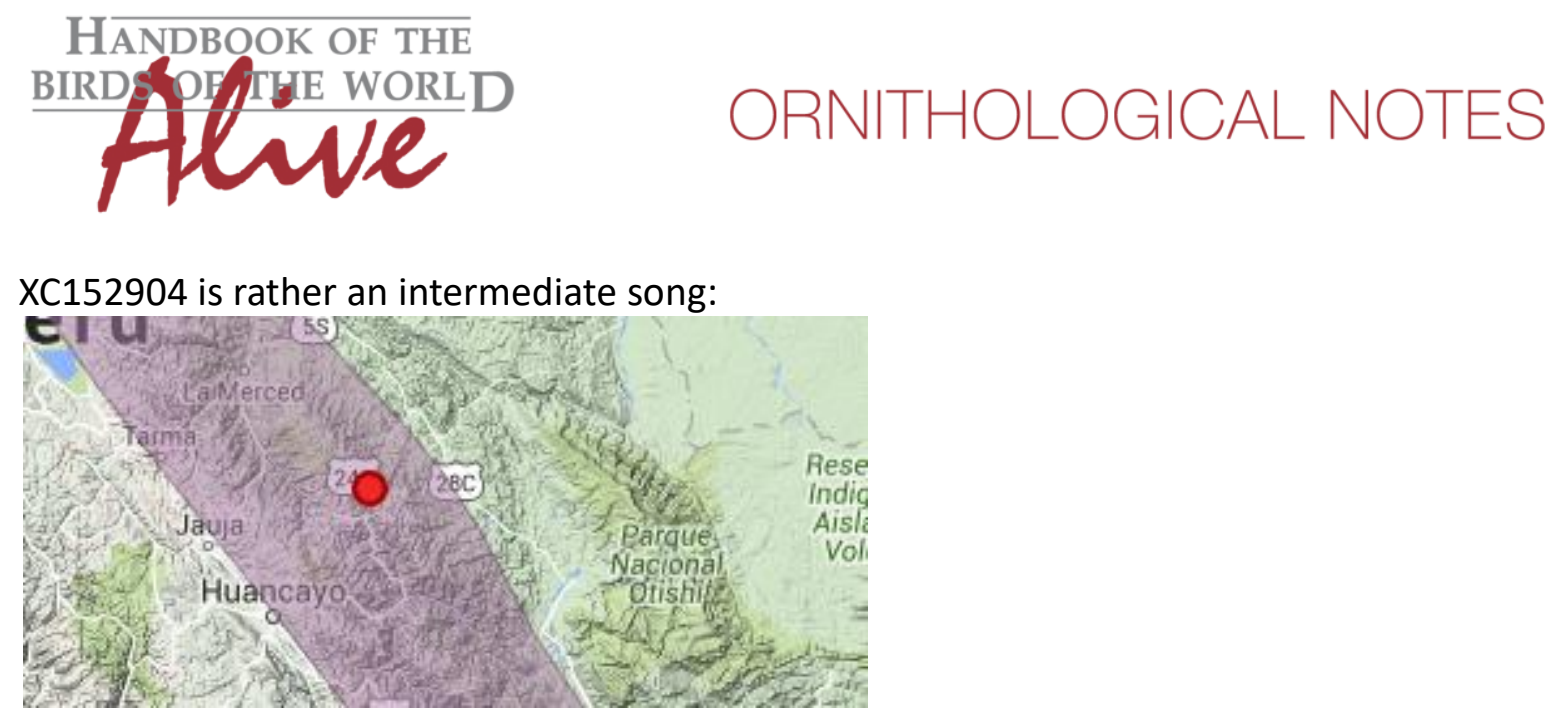

ML171867 has elements of both song-types:

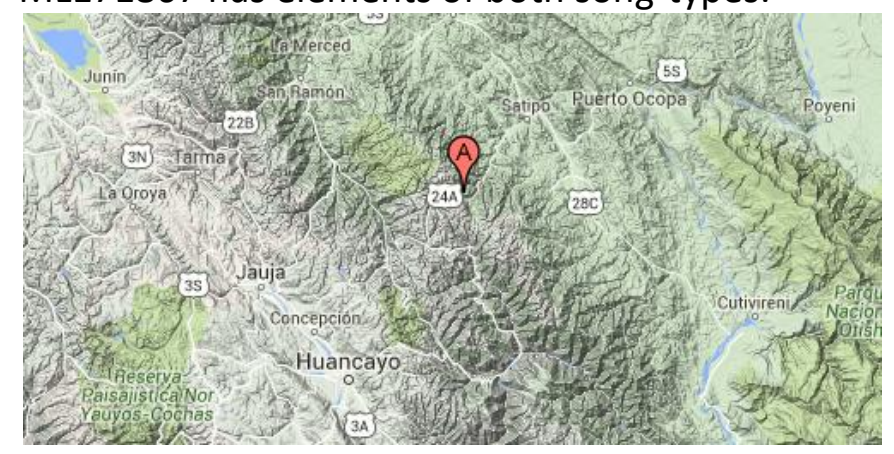

ML92123 is a rather typical igniventris song:

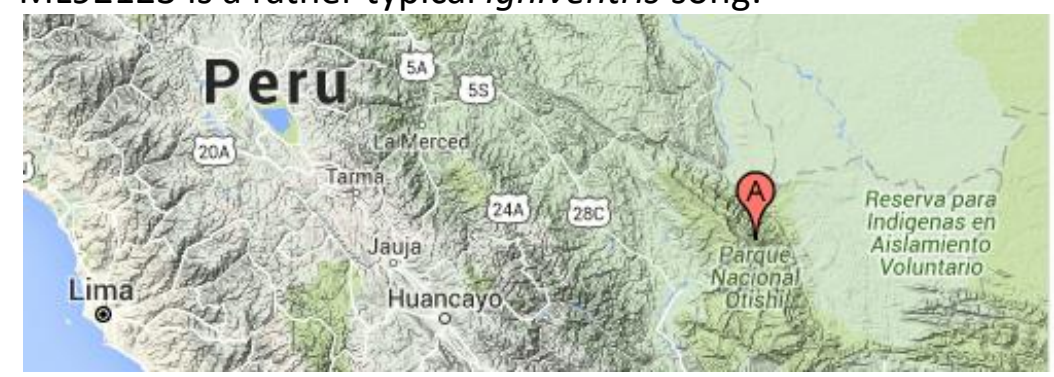

Further north and south there are no intermediate song types.

This note was finalized on 5th July 2016, using sound recordings available on-line at that moment. We would like to thank in particular the many sound recordists who placed their recordings for this species on $\mathrm{XC}$ and $\mathrm{ML}$.

\section{References}

Tobias, J.A., Seddon, N., Spottiswoode, C.N., Pilgrim, J.D., Fishpool, L.D.C. \& Collar, N.J. (2010). Quantitative criteria for species delimitation. Ibis 152(4): 724-746.

\section{Recommended citation}

Boesman, P. (2016). Notes on the vocalizations of Scarlet-bellied Mountain-tanager (Anisognathus igniventris). HBW Alive Ornithological Note 404. In: Handbook of the Birds of the World Alive. Lynx Edicions, Barcelona. (retrieved from http://www.hbw.com/node/1253798 on 2 December 2016). 